\title{
RESEARCH
}

Open Access

\section{Clinical profile of patients with ATP1A3 mutations in Alternating Hemiplegia of Childhood-a study of 155 patients}

Eleni Panagiotakaki ${ }^{*}$, Elisa De Grandis ${ }^{2}$, Michela Stagnaro $^{2}$, Erin L. Heinzen ${ }^{3,4}$, Carmen Fons ${ }^{5}$, Sanjay Sisodiya ${ }^{6}$, Boukje de Vries ${ }^{7}$, Christophe Goubau ${ }^{8}$, Sarah Weckhuysen ${ }^{9}$, David Kemlink ${ }^{10}$, Ingrid Scheffer ${ }^{11,12}$, Gaëtan Lesca ${ }^{13,14}$, Muriel Rabilloud ${ }^{15}$, Amna Klich ${ }^{15}$, Alia Ramirez-Camacho ${ }^{1,5}$, Adriana Ulate-Campos ${ }^{5}$, Jaume Campistol' ${ }^{5}$, Melania Giannotta ${ }^{16}$, Marie-Laure Moutard ${ }^{17}$, Diane Doummar ${ }^{17}$, Cecile Hubsch-Bonneaud ${ }^{18}$, Fatima Jaffer ${ }^{6}$, Helen Cross $^{19}$, Fiorella Gurrieri ${ }^{20}$, Danilo Tiziano ${ }^{20}$, Sona Nevsimalova ${ }^{10}$, Sophie Nicole ${ }^{21,22}$, Brian Neville ${ }^{19}$, Arn M. J. M. van den Maagdenberg ${ }^{7,23}$, Mohamad Mikatii ${ }^{24}$, David B. Goldstein ${ }^{3,4}$, Rosaria Vavassori ${ }^{25}$, Alexis Arzimanoglou, ${ }^{1,26}$, The Italian IBAHC Consortium, The French AHC Consortium and The International AHC Consortium

\begin{abstract}
Background: Mutations in the gene ATP1A3 have recently been identified to be prevalent in patients with alternating hemiplegia of childhood (AHC2). Based on a large series of patients with AHC, we set out to identify the spectrum of different mutations within the ATP1A3 gene and further establish any correlation with phenotype.

Methods: Clinical data from an international cohort of 155 AHC patients (84 females, 71 males; between 3 months and 52 years) were gathered using a specifically formulated questionnaire and analysed relative to the mutational ATP1A3 gene data for each patient.
\end{abstract}

Results: In total, 34 different ATP1A3 mutations were detected in $85 \%$ (132/155) patients, seven of which were novel. In general, mutations were found to cluster into five different regions. The most frequent mutations included: p.Asp801Asn (43\%; 57/132), p.Glu815Lys (16 \%; 22/132), and p.Gly947Arg (11\%; 15/132). Of these, p.Glu815Lys was associated with a severe phenotype, with more severe intellectual and motor disability. p.Asp801Asn appeared to confer a milder phenotypic expression, and p.Gly947Arg appeared to correlate with the most favourable prognosis, compared to the other two frequent mutations. Overall, the comparison of the clinical profiles suggested a gradient of severity between the three major mutations with differences in intellectual $(p=0.029)$ and motor $(p=0.039)$ disabilities being statistically significant. For patients with epilepsy, age at onset of seizures was earlier for patients with either p.Glu815Lys or p.Gly947Arg mutation, compared to those with p.Asp801Asn mutation $(p<0.001)$. With regards to the five mutation clusters, some clusters appeared to correlate with certain clinical phenotypes. No statistically significant clinical correlations were found between patients with and without ATP1A3 mutations.

\footnotetext{
* Correspondence: eleni.panagiotakaki@chu-lyon.fr

${ }^{1}$ Epilepsy, Sleep and Pediatric Neurophysiology Department (ESEFNP),

University Hospitals of Lyon (HCL), Lyon, France

Full list of author information is available at the end of the article
} 
(Continued from previous page)

Conclusions: Our results, demonstrate a highly variable clinical phenotype in patients with AHC2 that correlates with certain mutations and possibly clusters within the ATP1A3 gene. Our description of the clinical profile of patients with the most frequent mutations and the clinical picture of those with less common mutations confirms the results from previous studies, and further expands the spectrum of genotype-phenotype correlations. Our results may be useful to confirm diagnosis and may influence decisions to ensure appropriate early medical intervention in patients with AHC. They provide a stronger basis for the constitution of more homogeneous groups to be included in clinical trials.

Keywords: Alternating hemiplegia of childhood, ATP1A3, Genotype-phenotype

\section{Background}

Alternating hemiplegia of childhood (AHC) is a rare neurological disorder characterized by transient episodes of alternating hemiplegia/hemiparesis, dystonic attacks, paroxysmal abnormal ocular movements, epileptic seizures and episodes of autonomic dysfunction [1-3]. The disease usually starts before 18 months of life and in the majority of patients before the age of 6 months. Plegic and tonic attacks disappear with sleep $[4,5]$. Between attacks patients have an abnormal neurological examination often presenting ataxia, dystonia and other involuntary abnormal movements, and almost all present an intellectual disability [6, 7]. AHC has a prevalence of $1: 100,000$ children [8]. Our previous results emphasized the significant variability of the disease course between individuals and indicated no general pattern of progression [9].

Mutations have been identified in some AHC patients in the following genes: CACNA1A [10], SLC1A3 [11], SLC2A1 [12, 13], and ATP1A2 (AHC1, MIM number 104290) [14, 15]. The majority of these cases were atypical with features overlapping with either familial or non-familial hemiplegic migraine. Further studies in larger numbers of patients have failed to confirm a correlation between mutations in these genes and alternating hemiplegia of childhood [5, 9, 16-20].

In 2012, mutations in the ATP1A3 gene (MIM 182350), located at 19q13.2 [hg19], were identified as the primary cause of AHC [21-23] (AHC2, MIM 614820). Mutations in $A T P 1 A 3$ are found in approximately $75 \%$ of cases and the disease is transmitted as an autosomal dominant trait. The mutations are usually de novo, but some have been found to be transmitted to offspring [21]. The ATP1A3 gene (23 exons, ORF contains 3042 base-pairs) encodes the sodium-potassium $(\mathrm{Na}+/ \mathrm{K}+)$ ATPase $\alpha 3$ subunit (1014 amino acids) that contains 6 cytoplasmic, 10 helical and 5 extracellular domains. Mutations in the ATP1A3 gene, are also found in patients with dystonia 12 (rapidonset dystonia parkinsonism; RDP, MIM 128235) [24-27] and CAPOS (cerebellar ataxia, areflexia, pes cavus, optic atrophy and sensorineural hearing loss, MIM 601338) syndrome [28]. RDP is a non-dopa-responsive dystonia, with rapid onset of a few minutes to a few days before stabilization. The age at onset is between 9 months [29] and 59 years and triggering factors are physical (e.g. exercise or childbirth) or psychological stress. CAPOS syndrome is characterized by an early-childhood onset of recurrent episodes of acute ataxia associated with febrile illnesses. These acute episodes tend to decrease with time, but the neurologic sequelae are permanent and progressive, resulting in gait and limb ataxia and areflexia. Affected individuals also develop progressive visual impairment due to optic atrophy and sensorineural hearing loss beginning in childhood [28]. With the addition of our data, no less than 83 ATP1A3 mutations have been described in patients with these three disorders [30-41] (Additional file 1).

The present study describes data obtained from a large international cohort, which is, in part, based on the initial European web-based registries ENRAH (European Network for Research on Alternating Hemiplegia) [42] and nEUroped (European Network on Rare Paediatric Neurological Diseases) [43]. The aim was to identify possible correlations between clinical phenotype and different $A T P 1 A 3$ gene mutations. In addition, the phenotypes of patients with and without ATP1A3 mutations were also compared.

\section{Methods}

This work was based on the efforts of the International Consortium for the Research on AHC (IAHCRC [44]) formed in 2012 after the identification of mutations in $A T P 1 A 3$ in AHC patients. The group involves clinicians, geneticists and researchers from Europe, USA and Australia and works in close collaboration with patient organizations, most of whom had already participated in the ENRAH and nEUroped projects.

An AHC patient database was formed within the framework of these two projects, in which clinical data are continuously being updated. The medical data reported here were centralised from nine different countries: France (57 patients), Italy (41), Spain (16), United Kingdom (10), USA (8), The Netherlands (7), Belgium (7), Czech Republic (5) and Australia (4). 


\section{Inclusion criteria}

Diagnosis of AHC was based on Aicardi's criteria, as previously reported [4, 9]: (1) onset of paroxysmal events before 18 months of age; (2) repeated bouts of hemiplegia involving the right and left side of the body during some attacks; (3) episodes of bilateral hemiplegia or quadriplegia starting either as generalization of a hemiplegic episode or bilateral from the start; (4) other paroxysmal disturbances including tonic/dystonic attacks, nystagmus, strabismus, dyspnoea and other autonomic phenomena occurring during hemiplegic bouts or in isolation; (5) immediate disappearance of all symptoms upon sleep, with probable recurrence of long-lasting bouts, 10-20 min after awakening; (6) evidence of developmental delay, intellectual disability, neurological abnormalities, choreoathetosis and dystonia or ataxia; and (7) not attributable to other disorders.

\section{Phenotypic data-questionnaire}

To assess clinical phenotype, a questionnaire was designed (see Additional file 2).

Information was related to various time points or epochs: first, lifetime information concerning different signs and symptoms appearing at least once over a lifetime; second, time at inclusion in the database; and third, the time period between 6 and 12 years old. Lifetime information allowed us to investigate whether a sign/symptom was present previously, even if it was no longer present at the time of inclusion or at 6-12 years old. The time period of 6-12 years old was used in order to be able to compare data at a similar age, as subjects included had very different ages.

Details concerning paroxysmal and non-paroxysmal features were collected for all age epochs. For plegic and tonic attacks, the following details were noted: semiology, frequency, length and triggering events. The occurrence of an epileptic seizure, in contrast to other paroxysmal events, was considered when either the semiology of the event was definitively indicative, interictal EEG changes corroborated the clinical observations, or an epileptic event was confirmed by EEG.

Intellectual disability was categorized as "mild" (IQ of 50-69), "moderate" (IQ of 35-49), or "severe" (IQ less than 35). The questionnaire completed by the clinicians was based either on IQ tests, when available, or indirect estimation of the degree of intellectual disability from clinical description and information regarding educational placement and/or professional integration in adulthood.

\section{Data collection}

Data collection was undertaken by the delegated participating centre managers (one per reference centre), who completed the questionnaire either after direct contact with patients and/or after revision of medical records, using additional information provided by the treating physician (paediatric neurologist or neurologist) or family. National parent associations assisted in the collection of data.

Research was conducted in accordance with the Declaration of Helsinki, and all procedures were carried out with the adequate understanding and written consent of the subjects or their parents, according to the appropriate national ethical committees, in accordance with national legislation and regulations.

\section{Mutation analysis}

DNA was extracted from blood, saliva, or buccal specimens from the probands and parents using standard procedures. The 23 exons and immediately flanking splice sites were Sanger sequenced in proband DNA using the primers listed in Additional file 3. Technical details of methods were reported in our previous, primary publication [21]. The mutation analysis was extended wherever possible to the parents to define if the mutation was de novo. ATP1A3 mutations were considered as probably pathogenic if they had occurred de novo and if the prediction tools were in favour of a deleterious effect. To ensure no patients were analysed more than once in this study, patients with the same rare ATP1A3 mutation, or lack thereof, were first assessed where possible for identical dates of birth and gender. In cases where this approach could not be taken based on site specific patient confidentially rules, concordant patients were genotyped at a series of 13 polymorphic sites in the genome (Additional file 4) to establish all patients studied were unique.

SIFT, Polyphen-2 and Mutation Taster were used for in silico prediction of pathogenicity of the missense mutations.

Reference sequences for corresponding ATP1A3 transcript and protein were [NM_152296.3] and [Uniprot P13637], respectively.

Analysis of RNA processing was not performed in this study.

\section{Statistical analysis}

Quantitative characteristics were described by the quartiles and the minimum and maximum values. Box plots were used to represent the distributions.

Qualitative characteristics were described by the absolute and relative frequencies in each category. Horizontal bar plots were used to represent the repartition of the patients in the different categories. Statistical comparisons were performed when groups of patients with the three most frequent mutations (p.Asp801Asn, p.Glu815Lys, or p.Gly947Arg) were compared, as well as between patients with and without any mutation. 
Comparisons were performed for the time period between 6 and 12 years.

The Kruskal-Wallis test and the Fisher exact test were used for quantitative and qualitative characteristics, respectively. In order to take into account the multiplicity of the tests, the type-I error was controlled using the approach of Benjamin and Yekutieli [45].

Analysis was carried out using the $\mathrm{R}$ software, version 3.1.0 (Free Software Foundation).

\section{Results and discussion}

A total of 155 AHC patients (84 females and 71 males) were included. At inclusion, patients were aged between 3 months and 52 years.

Thirty-four different ATP1A3 mutations were detected in $85 \%(132 / 155)$ AHC patients. The most frequent were p.Asp801Asn (43\%, 57/132), p.Glu815Lys (16 \%, 22/132) and p.Gly947Arg (12 with c.2839G > A and three with c.2 $839 \mathrm{G}>\mathrm{C})(11 \%, 15 / 132)$. All patients with p.Gly947Arg were considered as a single group, regardless of the nucleotide substitution. Less frequent mutations were p.Gly755Ser (in three patients) and p.Ser137Tyr, p.Ser772Arg (one with
c.2314A > C and one with c.2316C > G), p.Asn773Ser, p.Thr804Ile, p.Ser811Pro, p.Val919del and p.Asp923Asn (each present in two patients). There were 21 more mutations find each one at one patient.

Clinical characteristics of patients harbouring the three most common mutations (p.Asp801Asn, p.Glu815Lys and p.Gly947Arg) and patients with no ATP1A3 mutation are shown in detail in the supplementary data (Additional file 5). For the period between 6 and 12 years, the age at which patient data was directly compared, information was available for 105 patients, and 63/105 (60\%) had one of the three most frequent mutations (38 with p.Asp801Asn, 14 with p.Glu815Lys and 11 with p.Gly947Arg).

\section{Genotype - phenotype correlations}

A summary of clinical features and further patient information is presented in Fig. 1 and Additional file 5. $P$ values are given only when differences were statistically significant.

As outlined in Fig. 1, comparison of the three most common mutations, p.Glu815Lys, p.Asp801Asn and p.Gly947Arg, revealed a gradient of severity of associated

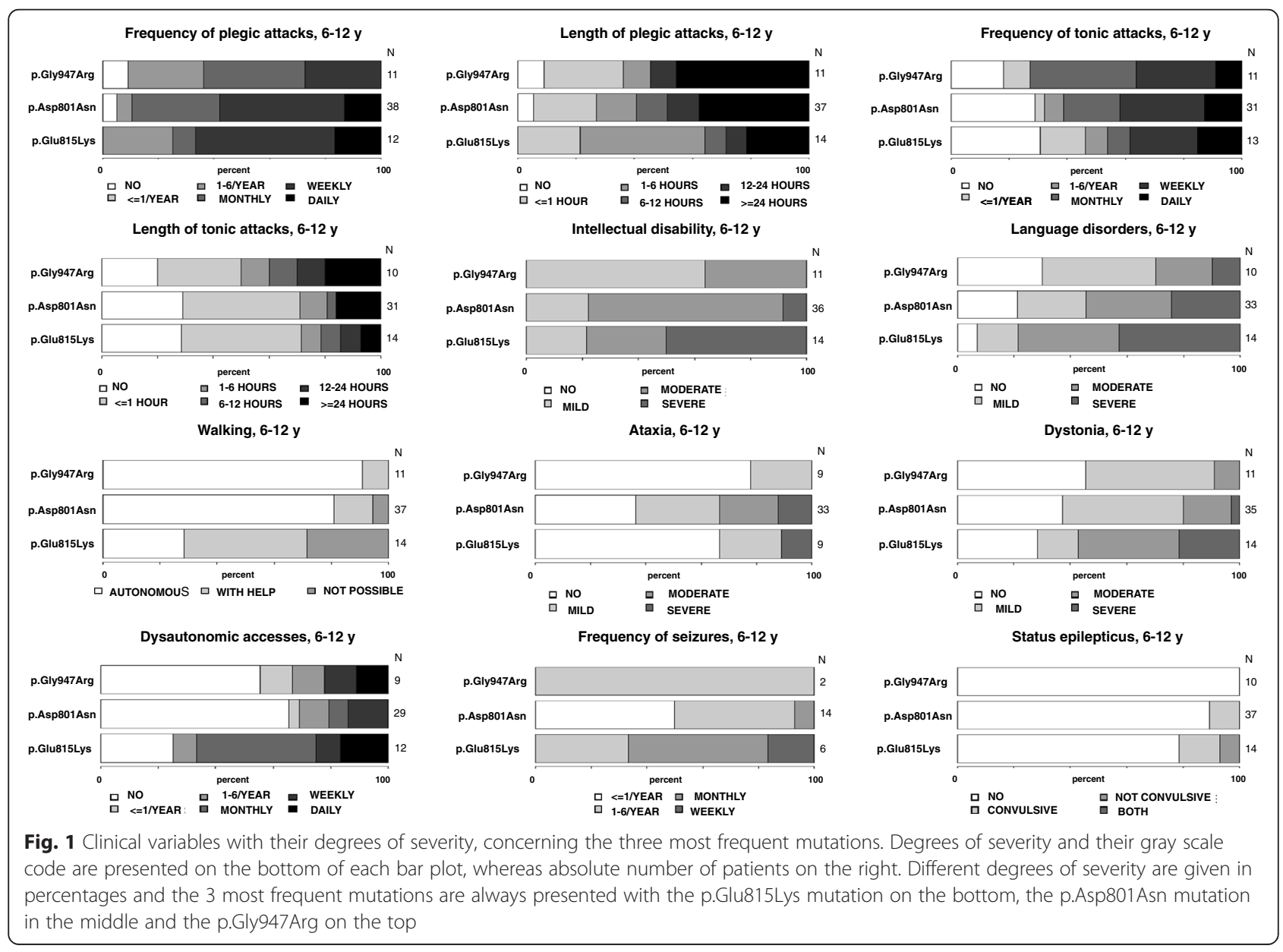


phenotypes. p.Glu815Lys was associated with the most severe phenotype, followed by p.Asp801Asn that appeared to confer a milder phenotypic expression, followed by p.Gly947Arg that correlated with the most favourable prognosis. The most pronounced differences regarding the severity of phenotypes between the three mutations were intellectual $(p=0.029)$ and motor $(p=$ $0.039)$ disability, as well as age at onset of seizures which was earlier for patients with either p.Glu815Lys or p.Gly947Arg mutation, compared to those with p.Asp801Asn mutation $(p<0.001)$. In addition, there were also apparent trends in differences of severity regarding other aspects of the disease (language, dystonia, autonomic dysfunction, epilepsy) (Fig. 1) however, these were not statistically significant, possibly due to the small number of patients.

Differences in the length and frequency of (hemi)plegic and tonic attacks was, however, less obvious. A plausible explanation for this could be the retrospective nature of the determination of the precise frequency and duration of attacks in patients that were ambulatory relative to those who were bedridden in settings in which these features may not have been specifically investigated.

\section{p.Glu815Lys mutation}

Patients with the p.Glu815Lys mutation tended to have an earlier age at the time of the first paroxysmal manifestation and first hemiplegic event, with frequent neonatal cases (Fig. 2a, b, Additional file 5). Relative to patients with p.Asp801Asn and p.Gly947Arg, they tended to have more frequent plegic attacks, but of shorter duration and less frequent dystonic attacks with a relatively short duration. Episodes of abnormal ocular movements occurred in almost the same percentage of patients with either of the three mutations.

p.Glu815Lys patients presented the most severe cognitive disability $(p=0.029)$, of whom half had severe and one third moderate intellectual disability. Likewise, $78 \%$ presented moderate or severe language problems (age
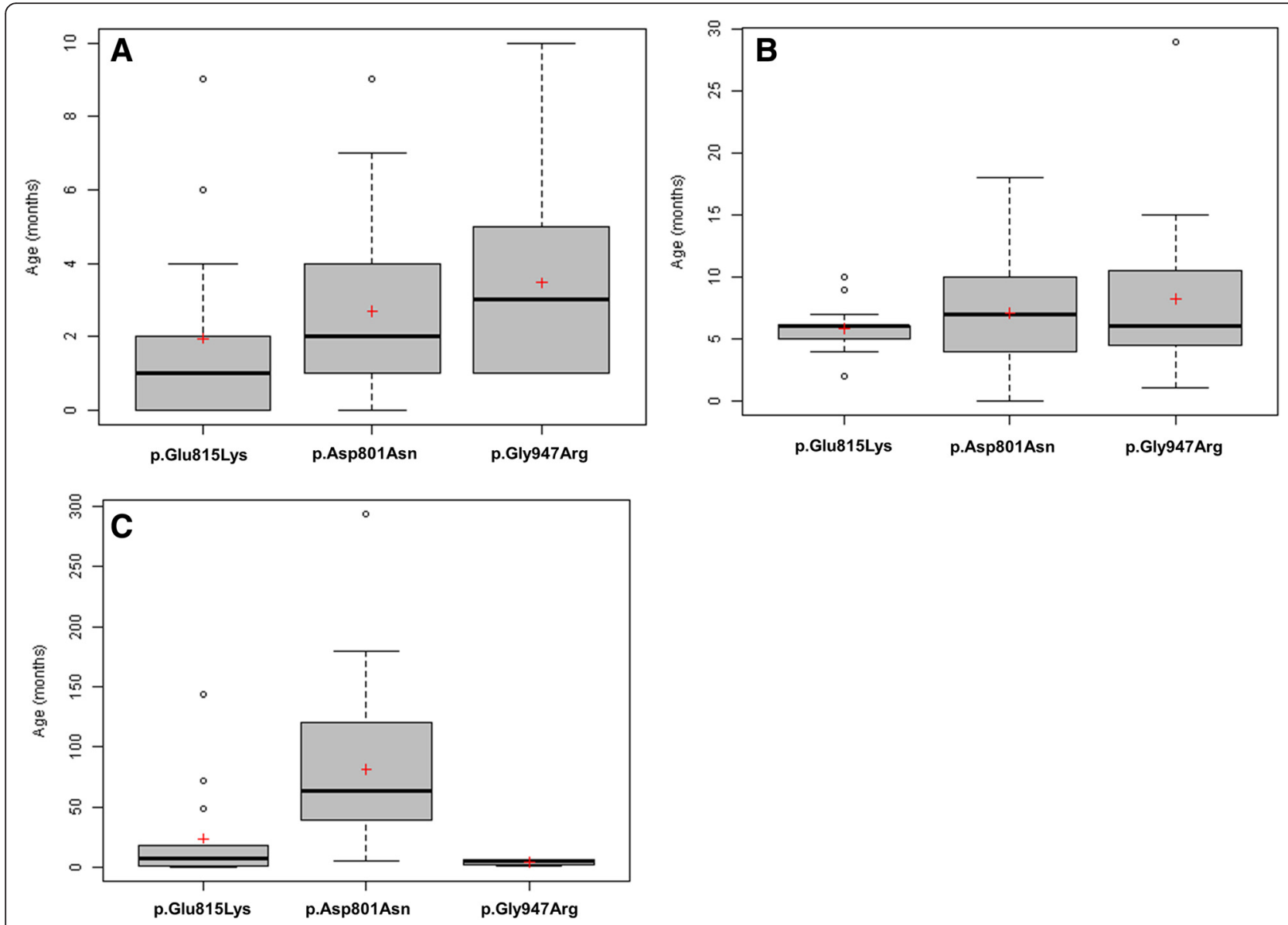

Fig. 2 Distribution of age in months at: first paroxysmal event $\mathbf{a}$, first plegic attack $\mathbf{b}$ and first epileptic seizures $\mathbf{c}$. Black lines represent medians and the red crosses represent means. Some isolated values (very high or very low) are represented by circles 
6-12 years). During adulthood, none of the seven adult p.Glu815Lys patients were ever employed.

Patients with the p.Glu815Lys mutation also presented the greatest motor disability (Fig. 1). At an age between 6 and 12 years old, nearly half of them walked only with assistance and one third were wheelchair-bound $(p=0.039)$. They also appeared to demonstrate a higher degree of regression with regards to walking over time, compared to patients with either of the two other mutations, however, the period in which this occurred was variable, making a comparison difficult.

The majority of patients with either of the three most frequent mutations presented movement disorders over their lifetime; 72-89 \% presented movement disorders between 6 and 12 years of age. More specifically, the majority $(71 \%)$ of p.Glu815Lys patients had dystonia at baseline (between paroxysmal events), and this was moderate to severe in $56 \%$ (Fig. 1). However, only a third of them presented ataxia.

A greater proportion of patients with p.Glu815Lys presented epilepsy and status epilepticus, relative to patients with either p.Asp801Asn or p.Gly947Arg (Additional file 5). The onset of seizures occurred earlier in life for patients with p.Glu815Lys (often during the first year of life), relative to patients with p.Asp801Asn $(p<0.001)$ (Fig. 2c).

At age 6-12 years, a majority (78 \%) of patients presented episodes of autonomic dysfunction and these patients presented more frequent attacks than patients with the other two mutations. This is speculated to be a precipitating factor for sudden death [9]. Four patients included in our cohort died; three had the p.Glu815Lys mutation and no mutation in the ATP1A3 gene was reported in the fourth deceased patient.

\section{p.Asp801Asn mutation}

For patients with the p.Asp801Asn mutation, first paroxysmal and hemiplegic events occurred at an older age (Fig. 2a, b, Additional file 5). They had less frequent plegic attacks than the p.Glu815Lys group, but of longer duration and slightly more frequent tonic attacks (Fig. 1).

The majority $(69 \%)$ presented with moderate intellectual disability $(p=0.029)$ and $54 \%$ had moderate or severe language problems (age 6-12 years). Among adult patients, one patient was independently employed and $25 \%$ (eight patients) were working in an assisted environment. Behavioural disorders were more common in patients with the p.Asp801Asn mutation (in more than half the patients) compared to those with the other two mutations.

The majority (81\%) of p.Asp801Asn patients were able to walk independently at the age of $6-12$ years $(p=0.039)$, but $63 \%$ presented ataxia. Hence, there were fewer dystonic patients with p.Asp801Asn, in comparison to p.Glu815Lys mutation, and patients with p.Asp801Asn presented mainly mild dystonia (Fig. 1).

Fewer patients with p.Asp801Asn mutation presented epilepsy and status epilepticus, in comparison to the p.Glu815Lys group, and patients had rather infrequent seizures (Additional file 5). They also had an onset of seizures later in life (median 5 years), relative to patients with either p.Glu815Lys or p.Gly947Arg mutations $(p<0.001)$.

At age 6-12 years, the proportion of patients with episodes of autonomic dysfunction (44\%) was almost half that of p.Glu815Lys patients and similar to that of the p.Gly947Arg group.

\section{p.Gly947Arg mutation}

In this group, first events occurred at an even later age, compared to those with either p.Glu815Lys or p.Asp801Asn, with sometimes very late onset of plegic attacks (Fig. 2a, b, Additional file 5). Furthermore, p.Gly947Arg patients had the least frequent plegic attacks, but had a tendency to present more frequent and longer tonic attacks (Fig. 1).

None of the patients had severe intellectual disability and the majority (63\%) had only mild intellectual disability $(p=0029)$. One of the five p.Gly947Arg adult patients was working in an assisted environment. At age 6-12 years, only $30 \%$ of the p.Gly 947 Arg group presented moderate or severe language problems. Of note, a large proportion of patients, each with one of the three mutations, presented dysarthria that could further complicate verbal communication even in patients with mild intellectual disability.

All but one p.Gly947Arg patients (91\%) walked independently at the age 6-12 years $(p=0.039)$. The remaining patient was able to walk with help. At baseline, p.Gly947Arg patients appeared the least ataxic and/or dystonic, compared to the two other groups (Fig. 1).

Fewer patients harbouring the p.Gly947Arg mutation presented epilepsy compared to the other two groups (Additional file 5, Fig. 1). Surprisingly, the onset of seizures for epileptic subjects with p.Gly947Arg occurred earlier in life, relative to patients with the other two mutations (even earlier than for p.Glu815Lys mutation) $(p<0.001)$. Patients with p.Gly947Arg presented autonomic attacks to the same extent as those with p.Asp801Asn patients.

Finally $\sim 15 \%$ of the analysed patients were negative to the molecular analysis of ATP1A3 gene. When the two groups were compared, no difference was observed regarding the frequency or length of plegic or tonic 
attacks, or the presence of abnormal ocular movements. Moreover, intellectual disability was similarly present in the majority of patients with and without ATP1A3 mutations (Additional file 5).

No difference was reported with regards to the acquisition of gait and presence of abnormal movements. Similarly, the incidence of epilepsy and status epilepticus was comparable between the two groups.

The absence of statistically significant differences between the mutated and non-mutated patients can be in part explained by the small sample size (with in particular a small number of patients without mutations) and also by the correction of the multiplicity of tests.

\section{Mutational clusters}

Heinzen et al. [21] first recognized that nearly all AHCcausing ATP1A3 mutations affect regions in or near transmembrane domains. Rosewich et al. [33] introduced the notion of mutational clusters. The observation of clustering was further confirmed in our cohort with the addition of new mutations. We have therefore further developed this notion within the ATP1A3 gene, and outline five mutational clusters situated and corresponding to the loop formed by an extracellular domain, the two adjacent transmembrane domains, as well as the surrounding regions of the cytoplasmic domain (Fig. 3). The distribution of the novel mutations identified in our study, together with those previously reported, suggests that AHC2 and RDP are associated with similar areas of mutation clusters (Fig. 3). The clinical presentation of patients grouped according to these mutational clusters was investigated in order to establish whether different clusters could be correlated with particular phenotypes. Similarities in clinical phenotype were observed between patients belonging to the same mutational cluster (Table 1).

\section{Interesting case reports within mutational clusters}

We report a novel mutation in cluster 2, p.Ala264_Ala289delinsValLeuGly, identified in a 34-year-old man with no intellectual disability (the patient had a degree in graphic design), but who presented motor regression due to progressive disabling dystonia. Whereas he was experiencing bouts of hemiplegic/dystonic attacks in a typical AHC manner, he also presented a bi-phasic severe permanent deterioration of his dystonia after stressful events during adolescence (minor head trauma at first and subsequent orthopaedic surgery with complications). We believe this patient presents an intermediate AHC2/RDP phenotype (Table 1). This case appears even more interesting if we consider that this cluster harbours many mutations associated with RDP [21, 26, 27] (Fig. 3).

With the exception of the p.Glu815Lys mutation, mutations in cluster 3 , especially those clustering at a location that corresponds to the transmembrane domain M6 (Fig. 3), are associated with mild-moderate phenotype, similar to p.Asp801Asn. Amino acid position 801 is a mutation hotspot and mutations occur at this position in both AHC2 (p.Asp801Asn, p.Asp801Glu, p.Asp801Tyr) [8, 21-23, 31, 33-35] and RDP (p.Asp801Tyr) [21, 26]. A novel p.Asp $801 \mathrm{Val}$ mutation was found in a patient with a particularly

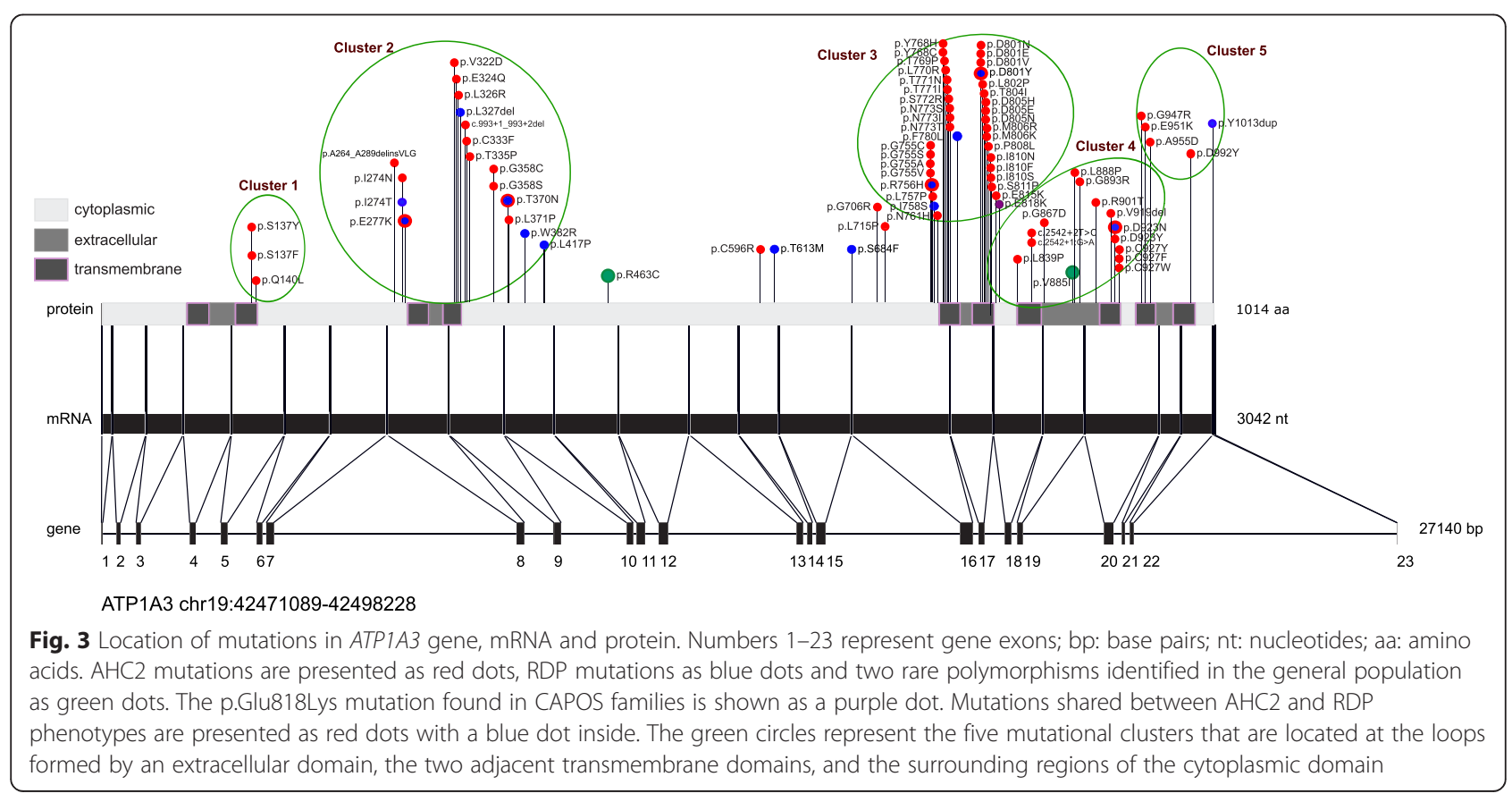


Table 1 Genotype-phenotype correlations

\begin{tabular}{|c|c|c|c|c|c|c|c|c|c|c|c|}
\hline \multirow[t]{2}{*}{ Genotype } & \multicolumn{11}{|c|}{ Phenotype of patients encountered in this study } \\
\hline & $\begin{array}{l}\text { Number } \\
\text { of patients }\end{array}$ & $\begin{array}{l}\text { Age at onset: first } \\
\text { event/first hemiplegic } \\
\text { attack }\end{array}$ & $\begin{array}{l}\text { Age at last } \\
\text { observation/ } \\
\text { Gender }\end{array}$ & $\begin{array}{l}\text { Intellectual } \\
\text { disability }\end{array}$ & $\begin{array}{l}\text { Walking } \\
\text { problems }\end{array}$ & Ataxia & Dystonia & $\begin{array}{l}\text { Hemiplegia/Double } \\
\text { hemiplegia attacks }\end{array}$ & $\begin{array}{l}\text { Tonic } \\
\text { attacks }\end{array}$ & Epilepsy & $\begin{array}{l}\text { Other } \\
\text { patients' } \\
\text { references }\end{array}$ \\
\hline \multicolumn{12}{|l|}{ Cluster 1} \\
\hline p.Ser137Phe & 1 & Unknown & $20 y / F$ & ++ & Unknown & + & + & ++++ & ++++ & ++ & {$[21,31]$} \\
\hline \multirow[t]{2}{*}{ p.Ser137Tyr } & 2 & $4 \mathrm{~m} / 4 \mathrm{~m}$ & $9 y / F$ & ++ & - & + & + & ++++ & Unknown & Remission & {$[21,34,35]$} \\
\hline & & & $2 y / M$ & + & + & & - & ++++ & - & - & \\
\hline \multicolumn{12}{|l|}{ Cluster 2} \\
\hline p.Ala264_Ala289delinsValLeuGly & 1 & $2 \mathrm{~m} / 2 \mathrm{~m}$ & $34 y / M$ & - & $\begin{array}{l}++ \text { (Regression- } \\
\text { lost walking) }\end{array}$ & - & +++ & + & + & - & \\
\hline p.lle274Asn & 1 & Neonatal / 33 m & $10 y / M$ & + & - & - & + & +++++ & + & - & {$[21,22,31]$} \\
\hline p.Glu324Gln & 1 & $1 \mathrm{~m} / 5 \mathrm{~m}$ & $16 y / M$ & +++ & ++ (Regression) & - & +++ & ++++ & ++++ & - & [31] \\
\hline p.Leu326Arg & 1 & $8 \mathrm{~m} / 15 \mathrm{~m}$ & $4 y / F$ & + & - & - & - & Remission & Remission & - & [31] \\
\hline c.993 + 1_993 + 2del $\$$ & 1 & $12 \mathrm{~m} / 12 \mathrm{~m}$ & $6 y / M$ & - & - & - & + & +++ & + & Remission & \\
\hline p.Cys333Phe & 1 & $1 \mathrm{~m} / 15 \mathrm{~m}$ & $4 y / M$ & + & + (Regression) & - & + & ++++ & +++ & Remission & {$[21,31]$} \\
\hline p.Gly358Ser & 1 & Neonatal / 6 years & $11 y / M$ & +++ & + & + & & +++++ & ++++ & ++++ & \\
\hline \multicolumn{12}{|c|}{ Cytoplasmic domain between Cluster 2 and 3} \\
\hline p.Cys596Arg & 1 & $1 \mathrm{~m} / 24 \mathrm{~m}$ & $21 y / M$ & +++ & - & + & + & +++ & +++ & + & [31] \\
\hline p.Leu715Pro $\$$ & 1 & Neonatal / 3 m & $2 y / M$ & ++ & ++ & + & + & +++++ & + & +++++ & \\
\hline \multicolumn{12}{|l|}{ Cluster 3} \\
\hline \multirow[t]{3}{*}{ p.Gly755Ser } & \multirow[t]{3}{*}{3} & $4 \mathrm{~m} / 5 \mathrm{~m}$ & $24 y / M$ & - & - & Unknown & ++ & +++++ & +++++ & Remission & \multirow{3}{*}{$\begin{array}{l}{[21,31,33-} \\
35]\end{array}$} \\
\hline & & $6 \mathrm{~m} / 8 \mathrm{~m}$ & $8 y / M$ & + & - & ++ & Unknown & ++++ & ++++ & ++ & \\
\hline & & $6 \mathrm{~m} / 6 \mathrm{~m}$ & $8 y / M$ & Unknown & - & + & - & ++++ & - & - & \\
\hline \multirow[t]{2}{*}{ p.Ser772Arg } & \multirow[t]{2}{*}{2} & $9 \mathrm{~m} / 9 \mathrm{~m}$ & $20 y / M$ & ++ & + & + & ++ & + & + & + & \multirow[t]{2}{*}[22,31,35]{} \\
\hline & & $5 \mathrm{~m} / 10 \mathrm{~m}$ & $7 y / M$ & ++ & - & - & ++ & ++++ & ++++ & - & \\
\hline \multirow[t]{2}{*}{ p.Asn773Ser } & \multirow{2}{*}{$\begin{array}{l}2 \text { mono- } \\
\text { zygotic } \\
\text { twins }\end{array}$} & Neonatal / 22 m & $10 y / F$ & + & - & - & - & ++ & + & Remission & \multirow[t]{2}{*}{ [21] } \\
\hline & & Neonatal / 22 m & $10 y / F$ & + & - & - & - & +++ & ++++ & Remission & \\
\hline p.Asp801Asn & 57 & $2 \mathrm{~m} / 7 \mathrm{~m}$ (medians) & $\begin{array}{l}\text { Median } \\
15.7 y\end{array}$ & ++ & - & +++ & ++ & ++++ & ++++ & + & $\begin{array}{l}{[8,21-23} \\
31,33-35]\end{array}$ \\
\hline p.Asp801Val ${ }^{\$}$ & 1 & $21 \mathrm{~m} / 21 \mathrm{~m}$ & $23 y / M$ & - & - & ++ & + & Remission & ++++ & - & \\
\hline \multirow[t]{2}{*}{ p.Thr804lle } & 2 & $2 \mathrm{~m} / 9 \mathrm{~m}$ & $13 y / F$ & + & - & - & + & ++ & ++ & - & \multirow[t]{2}{*}[31,33]{} \\
\hline & & $5 \mathrm{~m} / 5 \mathrm{~m}$ & $10 y / F$ & ++ & - & + & - & ++ & ++ & - & \\
\hline p.Met806Arg & 1 & $13 \mathrm{~m} / 13 \mathrm{~m}$ & $6 y / M$ & + & - & - & + & +++ & +++ & Remission & [21] \\
\hline p.lle810Asn ${ }^{ \pm}$ & 1 & $7 \mathrm{~m} / 8 \mathrm{~m}$ & $20 y / M$ & ++ & - & + & - & +++ & +++ & Remission & {$[35]$} \\
\hline
\end{tabular}


Table 1 Genotype-phenotype correlations (Continued)

\begin{tabular}{|c|c|c|c|c|c|c|c|c|c|c|c|}
\hline \multirow[t]{2}{*}{ p.Ser811Pro } & 2 & $1 \mathrm{~m} / 1 \mathrm{~m}$ & $24 y / F$ & ++ & + & ++ & ++ & +++++ & +++++ & ++ & {$[21,31]$} \\
\hline & & $1 \mathrm{~m} / 1 \mathrm{~m}$ & $20 y / F$ & ++ & ++ & + & ++ & ++++ & - & + & \\
\hline p.Glu815Lys & 22 & 1 m / 6 m (medians) & Median 7.8y & +++ & ++ & ++ & +++ & ++++ & ++++ & +++ & $\begin{array}{l}{[8,21-23} \\
31,33-35]\end{array}$ \\
\hline \multicolumn{12}{|l|}{ Cluster 4} \\
\hline p.Leu839Pro & 1 & Neonatal & $3 \mathrm{~m} / \mathrm{F}$ & NA & NA & NA & ++ & + & ++++ & - & {$[31,35]$} \\
\hline c. $2542+1 G>A$ & 1 & $1 \mathrm{~m} / 10 \mathrm{~m}$ & $26 y / F$ & ++ & + & - & + & + & - & +++ & $\begin{array}{l}{[21,22,31,} \\
33]\end{array}$ \\
\hline p.Leu888Pro $\$$ & 1 & $1 \mathrm{~m} / 7 \mathrm{~m}$ & $19 y / M$ & +++ & - & - & ++ & ++ & ++ & +++ & \\
\hline \multirow[t]{2}{*}{ p.Val919del } & 2 & Unknown & $3 y / F$ & +++ & ++ & & + & +++ & +++ & + & {$[21,31]$} \\
\hline & & Neonatal / 5 m & $17 y / M$ & ++ & - & - & ++ & ++++ & ++++ & - & \\
\hline \multirow[t]{2}{*}{ p.Asp923Asn } & 2 & $4 \mathrm{~m} / 29 \mathrm{~m}$ & $7 y / F$ & - & - & + & - & +++ & - & - & {$[34,35,40]$} \\
\hline & & $11 \mathrm{~m} / 24 \mathrm{~m}$ & $4 y / F$ & + & - & - & + & ++ & - & - & \\
\hline p.Cys927Phe & 1 & $18 \mathrm{~m} / 18 \mathrm{~m}$ & $15 y / F$ & ++ & - & + & - & Remission & +++++ & - & [34] \\
\hline p.Cys927Trp & 1 & $4 \mathrm{~m} / 4 \mathrm{~m}$ & $37 y / M$ & + & - & + & + & + & Remission & Remission & \\
\hline \multicolumn{12}{|l|}{ Cluster 5} \\
\hline p.Gly947Arg & 15 & 3 m / 6 m (medians) & Median 15y & + & - & + & + & +++ & +++ & + & $\begin{array}{l}{[8,21,31} \\
33-35]\end{array}$ \\
\hline p.Glu951Lys & 1 & $4 \mathrm{~m} / 10 \mathrm{~m}$ & $20 y / M$ & ++ & + & +++ & + & Remission & ++ & - & \\
\hline p.Ala955Asp & 1 & Neonatal & $4 y / M$ & +++ & ++ & - & + & +++++ & ++++ & ++ & {$[21]$} \\
\hline p.Asp992Tyr & 1 & $4 \mathrm{~m} / 8 \mathrm{~m}$ & $32 y / M$ & + & Unknown & Unknown & +++ & +++ & ++ & + & {$[21,34]$} \\
\hline
\end{tabular}

Novel mutations found in this study are given in bold characters. Of them, de novo mutations (both parents available and tested negative) are marked by the symbol $\mathrm{S} ; \mathrm{Y}:$ years, M: male, F: female, $\mathrm{m}$ : months; $\mathrm{f}$ :

p.lle810Asn (c.2429 T>A) corresponds to the Myshkin mice mutation; Remission, means no present at the last observation; First event: first paroxysmal event of the disease, either hemiplegic or other (i.e. abnormal ocular movements, double hemiplegia, tonic/dystonic attacks); Unknown: missed information; NA: not applicable because of young age at last observation. Reference sequences for corresponding ATP1A3 transcript and protein were [NM_152296.3] and [Uniprot P13637], respectively 
mild phenotype, presenting a late onset of symptoms at 21 months, no intellectual disability, independent walking and at 23 years old, no more hemiplegic attacks and only weekly dystonic episodes.

In cluster 1 (Fig. 3, Table 1), the p.Ser137Tyr substitution was previously reported to yield a severe phenotype [34], in contrast to our report of two patients with no major disability.

The p.Ile274Asn mutation in cluster 2 was previously reported to be associated with an unusual phenotype first described in a familial case, in which the index patient presented with late-onset episodes at 3 years of age and mild intellectual disability [21]. The patient with p.Ile274Asn mutation in our cohort had similar characteristics. In the same cluster the p.Leu326Arg mutation was present in one patient with only mild symptoms that resolved with use of flunarizine, with remission of hemiplegic attacks. Whereas a patient with the c.993 + 1_993 + 2del mutation had no intellectual disability, another with the p.Cys333Phe mutation had mild, and another with the p.Gly358Ser mutation exhibited severe intellectual disability, although hemiplegic attacks began unusually late in life in the latter.

Regarding cluster 3 (Fig. 3, Table 1), three patients harboured the mutation p.Gly755Ser. All three presented a mild phenotype. This is in contrast to a previous report in which this mutation was associated with a severe phenotype [34]. The p.Ser772Arg mutation was previously reported in a child with normal intellect [22], contrasting with two cases in our study presenting moderate intellectual disability.

Amino acid 927 is a mutation hotspot in cluster 4 . The p.Cys927Tyr and p.Cys927Phe mutations have previously been reported in patients with AHC $[23,34]$ and we identified a new mutation, p.Cys927Trp. The two patients harbouring the p.Cys927Phe and Cys927Trp mutations respectively had rare or no hemiplegic attacks with age.

The precise pathological mechanism resulting from ATP1A3 mutations so far remains obscure. Amino acids 801 and 947 are located on the transmembrane domains M6 and M9, respectively, whereas amino acid 815 has an intracellular location. It is so far unclear what effect these mutations have on the $\alpha 3$ subunit, but based on preliminary studies [21], protein expression levels appear to be largely unaffected. Such mutations may therefore lead to hypomorphic effects which may influence ATPase activity. Weigand and colleagues [46] initially suggested that binding of the $\alpha 3$ subunit to ouabain may play a possible pathophysiological role. However, unlike the p.Asp801Asn mutation, both the p.Glu815Lys and p.Gly947Arg mutations prevent binding of the $\alpha 3$ subunit to ouabain, yet these latter mutations, according to our results, were associated with very different phenotypes. Thus, although the role of endogenous ouabain should further be investigated, it cannot explain differences in phenotype alone. A more recent study [47] attempted to explore the molecular pathological mechanisms concerning the three most frequent mutations. Authors suggested that loss of forward cycling function was unlikely to underlie the observed clinical heterogeneity in AHC, and the extent of dominant negativity was similar between p.Asp801Asn, p.Gly947Arg and p.Glu815Lys. But proton current amplitude was profoundly reduced in the mutation p.Glu815Lys compared to p.Asp801Asn and p.Gly947Arg mutations.

The large multinational sample of AHC patients included in our study provides a statistically strong confirmation of the rate of different ATP $1 A 3$ mutations. Mutation in the ATP1A3 gene was identified in $85 \%$ patients $(78-100 \%$ in other series) $[8,21-23,31,33-$ $35,48]$, with the p.Asp801Asn, p.Glu815Lys and p.Gly947Arg mutations present in 43, 16 and $11 \%$, respectively (31-39 \%, 20-23\% and $15 \%$, in other series) $[33,35,48]$. Overall, 34 different mutations were identified, of which 7 have not been described previously.

Within the limit of our present knowledge, we have defined distinct clinical profiles for patients harbouring each of the three most frequent mutations, with the most severe phenotypic expression associated with p.Glu815Lys, followed by p.Asp801Asn and lastly p.Gly947Arg. The more pronounced phenotypic expression associated with p.Glu815Lys, relative to other ATP1A3 mutations, is in agreement with a recent study [31]. Previous studies in smaller cohorts of 35 and 51 patients, reported the severity of the p.Glu815Lys mutation concerning neonatal onset, motor disability and presence of status epilepticus and respiratory paralysis in the former [34] and a correlation with epilepsy in the latter [35]. The larger number of patients studied per mutation in this study provides a more comprehensive description of clinical profiles, allowing different clinical profiles to be compared.

We have further described a number of aspects of AHC that appear to be specific to certain mutations. Although some of the differences observed were not statistically significant, it should be emphasized that this may be due to the small number of patients with a given mutation, combined with the phenotypic complexity of the disorder. Indeed, when taken separately, the different major symptoms of AHC (such as epilepsy, movement disorders and cognition) are known to involve different neuronal networks, although these unavoidably interact. Such "symptoms" may even be considered as diseases per se. Each of these "major symptoms" may have their proper index of severity and it should be kept in mind that it is the combination of all these components that determines the severity of the AHC disorder as an entity. It could be hypothesized that a given mutation 
influences only one or more of these "major symptoms", while sparing others. If this is the case, only studies with much larger cohorts may eventually better highlight the specific role of each mutation.

\section{Conclusion}

Our study shows, based on a very extensive multinational cohort, that the phenotypic variation observed in AHC patients is mirrored in the heterogeneity of mutations affecting the ATP1A3 gene. We have described the clinical profiles of patients harbouring the three most frequent mutations (p.Glu815Lys, p.Asp801Asn and p.Gly947Arg) and reported extensive clinical information for patients with less common mutations, by considering the different mutations within specific clusters. Our results support the notion that, although it is clear that the $\alpha 3$ subunit is implicated in the pathogenesis of $\mathrm{AHC}$, the presence of individual variability in patients with the same mutation implies that other modifier genes or epigenetic factors play a role and this should be investigated in future studies.

\section{Appendix 1: The Italian IBAHC Consortium}

Maria Teresa Bassi, Renato Borgatti, Roberta Cernetti, Gabriella Di Rosa, Filippo Franchini, Antonio Gambardella, Manlio Giacanelli, Melania Giannotta, Giuseppe Gobbi, Tiziana Granata, Elisa De Grandis, Renzo Guerrini, Fiorella Gurrieri, Gemma Incorpora, Nardo Nardocci, Giovanni Neri, Francesca Ragona, Margherita Santucci, Stefano Sartori, Michela Stagnaro, Danilo Tiziano, Rosaria Vavassori, Edvige Veneselli, Federico Vigevano, Claudio Zucca.

\section{Appendix 2: The French AHC Consortium}

Aicardi J, An I, Arbues AS, Arzimanoglou A, BahiBuisson N, Barthez M-A, Billette de Villemeur T, Bourgeois M, Bru M, Chabrol B, Chaigne D, Chaunu MP, Chiron C, Cournelle AM, Davoine C-S, De St Martin A, Deny B, Desguerres I, Des Portes V, Doummar D, Dulac O, Dusser A, Gerard M, Gitiaux C, Godet Kiesel I, Gokben S (Turkey), Goutieres F, Guerrin M-H, Heron-Longe B, Hubsch-Bonneaud C, Hully $\mathrm{M}$, Husson $\mathrm{M}$, Ioos $\mathrm{Ch}$, Kaminska A, Laroche C, Lazaro L, Lepine A, Magy L, Marchal C, Michel J, Milh M, Motte J, Moutard ML, Napuri S, Nassogne MC (Belgium), Neau JP, Nicole S, Panagiotakaki E, Passemard S, Pedespan JM, PennielloValette MJ, Poncelin D, Ponsot G, Poulat A-L, Pouplard F, Rabilloud M, Riant F, Rivier F, Roelens P, Roubergue A, Sanlaville D, Tardieu M, Veyrieres S.

\section{Appendix 3: The International AHC Consortium}

Alexis Arzimanoglou (Scientific Coordinator), Rosaria Vavassori (Data Manager), Eleni Panagiotakaki (Node Coordinator, France), Elisa de Grandis (Node Coordinator
Italy), Carmen Fons (Node Coordinator Spain), Sanjay Sisodiya (Node Coordinator UK), Peter de Jonghe (Node Coordinator Belgium-Antwerp), Christophe Goubeau (Node Coordinator Belgium - Leuven), Arn M.J.M. van den Maagdenberg (Node Coordinator Leiden - The Netherlands), Mohamad Mikati (Node Coordinator USA), Ingrid Scheffer (Node Coordinator Australia), Sona Nevsimalova (Node Coordinator Czech Republic) and members of national centers not already figuring in national Consortia: David Kemlink and Anna Krepelova (Czech Republic); Miriam Kolnikova and Pavol Sykora (Slovakia); Juan Kaski, Michael Hanna and Henry Houlden (UK); Adriana Ulate-Campos, Ramón Cancho, Jesús Eiris, Eduardo López-Laso and Ramón Velázquez (Spain), Ines Carilho (Portugal), Laurie Ozelius, Mount Sinai School of Medicine, (USA); Arvid Suls and Berten Ceulemans (Belgium - Antwerp); Gunnar Buyse and Michela di Michele (Belgium-Leuven); Michel Ferrari and Cacha M.P.C.D. Peeters-Scholte (The Netherlands - Leiden).

\section{Additional files}

Additional file 1: Table of ATP1A3 mutations (in this study and in previous studies). (DOCX $31 \mathrm{~kb}$ )

Additional file 2: Clinical Information included in the Questionnaire. (DOCX $14 \mathrm{~kb}$ )

Additional file 3: Primers used to sequence the ATP1A3 exons and adjacent splice sites. (DOCX $18 \mathrm{~kb}$ )

Additional file 4: Taqman-based genotyping assays used to establish unique patient identities. (DOCX $17 \mathrm{~kb}$ )

Additional file 5: Clinical phenotype of patients with the three most common mutations, and of patients without and with mutations, in the ATP1A3 gene. (DOCX $46 \mathrm{~kb}$ )

\section{Abbreviations}

AHC: Aalternating hemiplegia of childhood; CAPOS syndrome: Cerebellar ataxia, areflexia, pes cavus, optic atrophy, sensorineural hearing loss; ENRAH: European Network for Research on Alternating Hemiplegia; IQ: Intellectual quotient; nEUroped: European Network on Rare Paediatric Neurological Diseases; RDP: Rapid-onset dystonia-parkinsonism.

\section{Competing interests}

The first author received a prize from the French Family Association for patients with AHC (AFHA) for her global contribution in research and care for children with AHC.

Dr. Sisodiya reports he is Patron of the UK support group, Alternating Hemiplegia of Childhood UK

Dr. Scheffer reports grants from NHMRC, grants from $\mathrm{NIH}$, during the conduct of the study; other from Annals of Neurology, other from Epileptic Disorders, other from Neurology, personal fees from UCB, personal fees from Athena Diagnostics, personal fees from Transgenomics, personal fees from GlaxoSmithKline, personal fees from Biocodex, outside the submitted work; In addition, Dr. Scheffer has a patent Diagnostic and Therapeutic Methods for EFMR (Epilepsy and Mental Retardation Limited to Females) with royalties paid.

Dr. Nicole received a grant from AFHA, association of French patients for the Establishment of the French biobank for genetic studies of AHC and reports a grant from AFM, association against myopathy to perform research on congenital myasthenic syndromes.

All other authors declare that they have no competing interests. 


\section{Authors' contributions}

EP compiled and analyzed all the data, wrote the first and all successive versions, integrated all comments and contributions; AA coordinated the IAHC Consortium, validated the data and contributed to all versions of the manuscript. EDG, MS, ELH, CF, SS, BdV, CG, SW, DK, IS, coordinated national nodes of the IAHCC, compiled relevant information and contributed in writing the manuscript; MR and AK provided the statistical analysis and reviewed the whole manuscript. GL, ARC, AUC, JC, MG, MLM, DD, CHB, FJ, HC, FG, DT, SNe compiled relevant information from the literature, provided details on individual patients included in the discussion and reviewed the manuscript. DBG, ELH, GL, SNi, AvdM, BdV, FG defined the genetic studies protocol and performed the genetic studies. BN, AvdM, MM, DBG provided guidance on clinical and genetic aspects and reviewed the manuscript. RV created and managed the patients' database. All members of the IBAHC, French AHC and International AHC Consortia contributed data and guidance. All authors read and approved the final manuscript.

\section{Acknowledgments}

We acknowledge the continuous support and work of Dr. Tsveta Schyns, founder and coordinator of the European Network for Research on Alternating Hemiplegia ENRAH; the ENRAH and nEUroped networks; The European Commission; The members of the French Association AFHA; The members of the Italian Association A.I.S.EA; The members of the Spanish Association AESHA.

Mr Siggi Johannesson, President of the Icelandic Association AHCAI, who supported the teleconference meetings of the Consortium.

We also thank individuals who particularly contributed to and supported the efforts of the ATP1A3 International AHC Consortium in collecting data and preparing the manuscript: Molly Cook and Yujun Han of Duke University; Filippo Franchini (AISEA); Doctors Teresa Escobar, Hedia Klaa, Sara Olivotto, Francesco Cardona, Alfonso Romano and Dante Galeone; Mr. Patrick Rollet (France) for artwork in figures; All our patients and their families; Bio-English (http://www.bio-english.com) for language reviewing.

The Italian IBAHC Consortium: The members of the Italian IBAHC Consortium are listed in the Appendix 1.

The French AHC Consortium: The members of the French AHC Consortium are listed in the Appendix 2.

The International AHC Consortium: The members of the International AHC Consortium are listed in the Appendix 3.

\section{Funding}

The cohort was based on the initial European web-based registries ENRAH (European Network for Research on Alternating Hemiplegia) and nEUroped (European Network on Rare Paediatric Neurological Diseases), funded by the sixth Framework Program of the European Commission between 2005 and 2007 and the Public Health Program 2007 (2008-2011), respectively. Additional funds were provided by national parent associations.

\section{Author details}

${ }^{1}$ Epilepsy, Sleep and Pediatric Neurophysiology Department (ESEFNP), University Hospitals of Lyon (HCL), Lyon, France. ${ }^{2}$ Department of Child Neuropsychiatry, G. Gaslini Hospital, University of Genoa, Genoa, Italy. ${ }^{3}$ Center for Human Genome Variation, Duke University School of Medicine, Durham, NC, USA. ${ }^{4}$ Department of Medicine, Duke University School of Medicine, Durham, NC, USA. ${ }^{5}$ Department of Child Neurology, Sant Joan de Déu Hospital, Barcelona, Spain. ${ }^{6}$ Department of Clinical and Experimental Epilepsy, University College London Institute of Neurology, London, UK. ${ }^{7}$ Department of Human Genetics, Leiden University Medical Centre, Leiden, The Netherlands. ${ }^{8}$ Department of Child Neurology, University Hospitals Leuven, Leuven, Belgium. ${ }^{9}$ Department of Molecular Genetics, Neurogenetics Group, VIB, Antwerp, Belgium. ${ }^{10}$ Department of Neurology, Charles University, First Faculty of Medicine and Teaching Hospital, Prague, Czech Republic.

${ }^{11}$ Department of Medicine, University of Melbourne, Austin Health, Melbourne, Australia. ${ }^{12}$ Department of Paediatrics, University of Melbourne, Royal Children's Hospital, Melbourne, Australia. ${ }^{13}$ Department of Genetics, University Hospitals of Lyon (HCL) and Claude Bernard Lyon I University, Lyon, France. ${ }^{14}$ Lyon Neuroscience Research Center (CRNL), CNRS UMR 5292, INSERM U1028, Lyon, France. ${ }^{15}$ Biostatistics Department, University Hospitals of Lyon and UMR 5558, Lyon, France. ${ }^{16}$ Child Neurology Unit, Maggiore Hospital, Bologna, Italy. ${ }^{17}$ Department of Child Neurology, Armand Trousseau Hospital, APHP, Paris, France. ${ }^{18}$ Department of Neurology, Pitié-Salpêtrière
Hospital, APHP, Paris, France. ${ }^{19}$ Institute of Child Health, University College London, London, UK. ${ }^{20}$ Institute of Medical Genetics, University Cattolica del Sacro Cuore, Policlinics A. Gemelli, Rome, Italy. ${ }^{21}$ Institut National de la Santé et de la Recherche Médicale, U975, Centre de Recherche de I'Institut du Cerveau et de la Moelle, Paris, France. ${ }^{22}$ Centre National de la Recherche Scientifique, UMR7225, Paris, France. ${ }^{23}$ Department of Neurology, Leiden University Medical Centre, Leiden, The Netherlands. ${ }^{24}$ Division of Pediatric Neurology and Department of Neurobiology, Duke University, School of Medicine, Durham, NC, USA. ${ }^{25}$ Associazione Italiana per la Sindrome di Emiplegia Alternante (A.I.S.EA Onlus), Lecco, Italy. ${ }^{26}$ DYCOG team, Lyon Neuroscience Research Centre (CRNL), INSERM U1028; CNRS UMR 5292, Lyon, France.

Received: 11 March 2015 Accepted: 1 September 2015

Published online: 26 September 2015

\section{References}

1. Verret S, Steele JC. Alternating hemiplegia in childhood: a report of eight patients with complicated migraine beginning in infancy. Pediatrics. 1971:47:675-80.

2. Dittrich J, Havlová M, Nevsímalová S. Paroxysmal hemipareses in childhood. Dev Med Child Neurol. 1979;21:800-7.

3. Krägeloh I, Aicardi J. Alternating hemiplegia in infants: report of five cases. Dev Med Child Neurol. 1980;22:784-91.

4. Aicardi J, Bourgeois M, Goutières F. Alternating hemiplegia of childhood: clinical findings and diagnostic criteria. In: Andermann F, Aicardi J, Vigevano F, editors. Alternating hemiplegia of childhood. New York: Raven; 1995. p. 3-18.

5. Sweney MT, Silver K, Gerard-Blanluet M, Pedespan JM, Renault F, Arzimanoglou A, et al. Alternating hemiplegia of childhood: early characteristics and evolution of a neurodevelopmental syndrome. Pediatrics. 2009;123:e534-41.

6. Bourgeois M, Aicardi J, Goutières F. Alternating hemiplegia of childhood. J Pediatr. 1993;122:673-9

7. Mikati MA, Kramer U, Zupanc ML, Shanahan RJ. Alternating hemiplegia of childhood: clinical manifestations and long-term outcome. Pediatr Neurol. 2000;23:134-41.

8. Hoei-Hansen CE, Dali CÍ, Lyngbye TJ, Duno M, Uldall P. Alternating hemiplegia of childhood in Denmark: clinical manifestations and ATP1A3 mutation status. Eur J Paediatr Neurol. 2014;18:50-4.

9. Panagiotakaki E, Gobbi G, Neville B, Ebinger F, Campistol J, Nevsímalová S, et al. Evidence of a non-progressive course of alternating hemiplegia of childhood: study of a large cohort of children and adults. Brain. 2010:133:3598-610

10. de Vries B, Stam AH, Beker F, van den Maagdenberg AM, Vanmolkot KR, Laan $L$, et al. CACNA1A mutation linking hemiplegic migraine and alternating hemiplegia of childhood. Cephalalgia. 2008;28:887-91.

11. Jen JC, Wan J, Palos TP, Howard BD, Baloh RW. Mutation in the glutamate transporter EAAT1 causes episodic ataxia, hemiplegia, and seizures. Neurology. 2005;65:529-34

12. Rotstein M, Doran J, Yang H, Ullner PM, Engelstad K, De Vivo DC. Glut1 deficiency and alternating hemiplegia of childhood. Neurology. 2009;73:2042-4.

13. Weller CM, Leen WG, Neville BG, Duncan JS, de Vries B, Geilenkirchen MA, et al. A novel SLC2A1 mutation linking hemiplegic migraine with alternating hemiplegia of childhood. Cephalalgia. 2015;35:10-5.

14. Bassi MT, Bresolin N, Tonelli A, Nazos K, Crippa F, Baschirotto C, et al. A novel mutation in the ATP1A2 gene causes alternating hemiplegia of childhood. J Med Genet. 2004:41:621-8.

15. Swoboda KJ, Kanavakis E, Xaidara A, Johnson JE, Leppert MF, Schlesinger-Massart MB, et al. Alternating hemiplegia of childhood or familial hemiplegic migraine? A novel ATP1A2 mutation. Ann Neurol. 2004:55:884-7.

16. Haan J, Kors EE, Terwindt GM, Vermeulen FL, Vergouwe MN, van den Maagdenberg $\mathrm{AM}$, et al. Alternating hemiplegia of childhood: no mutations in the familial hemiplegic migraine CACNA1A gene. Cephalalgia. 2000:20:696-700

17. de Vries B, Haan J, Stam AH, Vanmolkot KR, Stroink H, Laan LA, et al. Alternating hemiplegia of childhood: no mutations in the glutamate transporter EAAT1. Neuropediatrics. 2006;37:302-4. 
18. Vuillaumier-Barrot S, Panagiotakaki E, Le Bizec C, El Baba C, ENRAHs for SME Consortium, Fontaine $B$, et al. Absence of mutation in the SLC2A1 gene in a cohort of patients with alternating hemiplegia of childhood (AHC). Neuropediatrics. 2010:41:267-9.

19. De Grandis E, Stagnaro M, Biancheri R, Giannotta M, Gobbi G, Traverso M, et al. Lack of SLC2A1 (glucose transporter 1) mutations in 30 Italian patients with alternating hemiplegia of childhood. J Child Neurol. 2013;28:863-6.

20. Kors EE, Vanmolkot KR, Haan J, Kheradmand Kia S, Stroink H, Laan LA, et al. Alternating hemiplegia of childhood: no mutations in the second familial hemiplegic migraine gene ATP1A2. Neuropediatrics. 2004;35:293-6.

21. Heinzen EL, Swoboda KJ, Hitomi Y, Gurrieri F, Nicole S, de Vries B, et al. De novo mutations in ATP1A3 cause alternating hemiplegia of childhood. Nat Genet. 2012;44:1030-4.

22. Rosewich $H$, Thiele $H$, Ohlenbusch $A$, Maschke $U$, Altmüller J, Frommolt $P$, et al. Heterozygous de-novo mutations in ATP1A3 in patients with alternating hemiplegia of childhood: a whole-exome sequencing gene-identification study. Lancet Neurol. 2012;11:764-73.

23. Ishii A, Saito $Y$, Mitsui J, Ishiura H, Yoshimura J, Arai $H$, et al. Identification of ATP1A3 mutations by exome sequencing as the cause of alternating hemiplegia of childhood in Japanese patients. PLoS One. 2013;8, e56120.

24. Dobyns WB, Ozelius LJ, Kramer PL, Brashear A, Farlow MR, Perry TR, et al. Rapid-onset dystonia parkinsonism. Neurology. 1993;43:2596-602.

25. Brashear A, DeLeon D, Bressman SB, Thyagarajan D, Farlow MR, Dobyns WB. Rapid-onset dystonia-parkinsonism in a second family. Neurology. 1997:48:1066-9.

26. de Carvalho Aguiar P, Sweadner KJ, Penniston JT, Zaremba J, Liu L, Caton M, et al. Mutations in the $\mathrm{Na}+/ \mathrm{K}+-$ ATPase alpha3 gene ATP1A3 are associated with rapid-onset dystonia parkinsonism. Neuron. 2004;43:169-75.

27. Brashear A, Dobyns WB, de Carvalho Aguiar P, Borg M, Frijns CJ, Gollamudi $\mathrm{S}$, et al. The phenotypic spectrum of rapid-onset dystonia-parkinsonism (RDP) and mutations in the ATP1A3 gene. Brain. 2007;130:828-35.

28. Demos MK, van Karnebeek CD, Ross CJ, Adam S, Shen Y, Zhan SH, et al. A novel recurrent mutation in ATP1A3 causes CAPOS syndrome. Orphanet J Rare Dis. 2014;9:15.

29. Brashear A, Mink JW, Hill DF, Boggs N, McCall WV, Stacy MA, et al. ATP1A3 mutations in infants: a new rapid-onset dystonia-Parkinsonism phenotype characterized by motor delay and ataxia. Dev Med Child Neurol. 2012;54:1065-7.

30. Boelman C, Lagman-Bartolome AM, MacGregor DL, McCabe J, Logan WJ, Minassian BA. Identical ATP1A3 mutation causes alternating hemiplegia of childhood and rapid-onset dystonia parkinsonism phenotypes. Pediatr Neurol. 2014:51:850-3.

31. Viollet L, Glusman G, Murphy KJ, Newcomb TM, Reyna SP, Sweney M, et al. Alternating hemiplegia of childhood: retrospective genetic study and genotype-phenotype correlations in 187 subjects from the US AHCF registry. PLoS One. 2015;10, e0127045.

32. Kamm C, Fogel W, Wächter T, Schweitzer K, Berg D, Kruger R, et al. Novel ATP1A3 mutation in a sporadic RDP patient with minimal benefit from deep brain stimulation. Neurology. 2008;70:1501-3.

33. Rosewich H, Ohlenbusch A, Huppke P, Schlotawa L, Baethmann M, Carrilho I, et al. The expanding clinical and genetic spectrum of ATP1A3-related disorders. Neurology. 2014;82:945-55.

34. Sasaki M, Ishii A, Saito Y, Morisada N, lijima K, Takada S, et al. Genotype-phenotype correlations in alternating hemiplegia of childhood. Neurology. 2014;82:482-90.

35. Yang X, Gao H, Zhang J, Xu X, Liu X, Wu X, et al. ATP1A3 mutations and genotype-phenotype correlation of alternating hemiplegia of childhood in Chinese patients. PLoS One. 2014;9, e97274.

36. Svetel M, Ozelius LJ, Buckley A, Lohmann K, Brajković L, Klein C, et al. Rapid onset dystonia-parkinsonism: case report. J Neurol. 2010;257:472-4.

37. Rosewich H, Weise D, Ohlenbusch A, Gärtner J, Brockmann K. Phenotypic overlap of alternating hemiplegia of childhood and CAPOS syndrome. Neurology. 2014;83:861-3

38. Rosewich H, Baethmann M, Ohlenbusch A, Gärtner J, Brockmann K. A novel ATP1A3 mutation with unique clinical presentation. J Neurol Sci. 2014;341:133-5.

39. Anselm IA, Sweadner KJ, Gollamudi S, Ozelius LJ, Darras BT. Rapid-onset dystonia parkinsonism in a child with a novel atp1a3 gene mutation. Neurology. 2009;73:400-1.

40. Roubergue A, Roze E, Vuillaumier-Barrot S, Fontenille MJ, Méneret A, Vidailhet $M$, et al. The multiple faces of the ATP1A3-related dystonic movement disorder. Mov Disord. 2013;28:1457-9.
41. Blanco-Arias $P$, Einholm AP, Mamsa H, Concheiro C, Gutiérrez-de-Terán $H$, Romero J, et al. A C-terminal mutation of ATP1A3 underscores the crucial role of sodium affinity in the pathophysiology of rapid-onset dystonia parkinsonism. Hum Mol Genet. 2009;18:2370-7.

42. European Network for Research on Alternating Hemiplegia. Accessed 9 September 2015. [http://www.enrah.net]

43. European Network for Rare Paediatric Neurological Diseases (nEUroped). Accessed 9 September 2015. [http://www.eurordis.org/content/europeannetwork-rare-paediatric-neurological-diseases-neuroped]

44. IAHCRC International Consortium research and care for the ATP1A3 diseases. Accessed 9 September 2015. [http://www.iahcrc.net]

45. Benjamini $Y$, Yekutieli D. The control of the false dicovery rate in multiple testing under dependency. Ann Stat. 2001;29:1165-88.

46. Weigand KM, Messchaert M, Swarts HG, Russel FG, Koenderink JB. Alternating hemiplegia of childhood mutations have a differential effect on $\mathrm{Na}(+), \mathrm{K}(+)$-ATPase activity and ouabain binding. Biochim Biophys Acta. 1842;2014:1010-6.

47. Li M, Jazayeri D, Corry B, McSweeney KM, Heinzen EL, Goldstein DB, et al. A functional correlate of severity in alternating hemiplegia of childhood. Neurobiol Dis. 2015;77:88-93.

48. Heinzen EL, Arzimanoglou A, Brashear A, Clapcote SJ, Gurrieri F, Goldstein DB, et al. Distinct neurological disorders with ATP1A3 mutations. Lancet Neurol. 2014;13:503-14.

\section{Submit your next manuscript to BioMed Central and take full advantage of:}

- Convenient online submission

- Thorough peer review

- No space constraints or color figure charges

- Immediate publication on acceptance

- Inclusion in PubMed, CAS, Scopus and Google Scholar

- Research which is freely available for redistribution 